\title{
Comparison of Spatial Pattern and Mechanism between Convexity and Gap Winds
}

\author{
Akifumi Nishi ${ }^{1}$ and Hiroyuki Kusaka ${ }^{2}$ \\ ${ }^{1}$ Graduate School of Life and Environmental Sciences, University of Tsukuba, Tsukuba, Japan \\ ${ }^{2}$ Center for Computational Sciences, University of Tsukuba, Tsukuba, Japan
}

\begin{abstract}
This study uses a numerical model to examine how a convex feature and a gap feature in a mountain range affect the leeward wind field. In the "convexity case", the mountain ridge has a convex feature (viewed from above). In the "gap case", the mountain ridge has a gap. The results show that both cases have local winds at the surface exceeding $8 \mathrm{~m} \mathrm{~s}^{-1}$, and both have similar spatial flow-patterns. However, the momentum budgets at the strongwind regions differ between the cases. In the convexity case, the downdrafts are important in the momentum balance, whereas in the gap case, both the downdrafts and the pressure-gradient force are important. Thus, although their spatial patterns of surface wind are similar to each other, their mechanisms for producing a strong local wind differ.

Sensitivity experiments of $F r_{m}$ show that strong-wind appears in both the convexity and gap cases when $F r_{m}$ is between 0.42 and 1.04. In contrast, when $F r_{m}$ is 0.21 , strong winds only appear in the gap case because the flow can go around the gap. When $F r_{m}$ exceeds 1.25 , strong surface winds appear in the entire leeward plain.
\end{abstract}

(Citation: Nishi, A., and H. Kusaka, 2019: Comparison of spatial pattern and mechanism between convexity and gap winds. SOLA, 15, 12-16, doi:10.2151/sola.2019-003.)

\section{Introduction}

Mountain ridges are often associated with local strong winds. When air flows over a ridge, the lee-side slope may have a strong wind called a "downslope windstorm" (e.g., Long 1952; Lilly and Zipser 1972; Peltier and Clark 1979; Clark and Peltier 1984; Smith 1985; Saito and Ikawa 1991; Saito 1993; Lin and Wang 1996; Gohm et al. 2008; Elvidge and Renfrew 2016; Miltenberger et al. 2016). A gap in a mountain range can also produce a strong wind called a "gap wind" (e.g., Scorer 1952; Arakawa 1969; Lackmann and Overland 1989; Zängl. 2003; Gaberšek and Durran 2004; Mayr et al 2004; Sasaki et al. 2010; Mass et al. 2014).

The similarity and difference between the downslope windstorm and gap winds showed in many studies from the flow pattern and momentum balance. Arakawa (1969) showed the similarity of downslope windstorms and gap winds using the shallow water theory. When subcritical flows in the windward region change into critical flows at the mountain top (or the narrowest point of the gap), strong supercritical flows appear in the lee of mountain (or the gap exit).

According to numerical simulations of stratified atmosphere and momentum budget analysis by Gaberšek and Durran (2004), gap winds have similar feature to the flows over the mountain range when mountain Froude number $\left(F r_{m}=U / N M_{h}, U, N\right.$, and $M_{h}$ are windspeed, Brant-Vaisala frequency, and the ridge height, respectively) exceeds about 1.0. When the $F r_{m} \approx 1.0$, the flows are like downslope windstorms (the mountain-wave regime). When the $F r_{m} \gg 1.0$, the flows are like potential-flows (the linear regime).

A convex feature in a mountain range (e.g., Fig. 1a) may also produce a local strong wind in the mountains' leeward plain.

Corresponding author: Hiroyuki Kusaka, University of Tsukuba, 1-1-1 Tennodai, Tsukuba, Ibaraki 302-8577, Japan. E-mail: kusaka@ccs.tsukuba. ac.jp.

CThe Author(s) 2019. This is an open access article published by the Meteorological Society of Japan under a Creative Commons Attribution 4.0 International (CC BY 4.0) license (http://creativecommons.org/license/by/4.0).
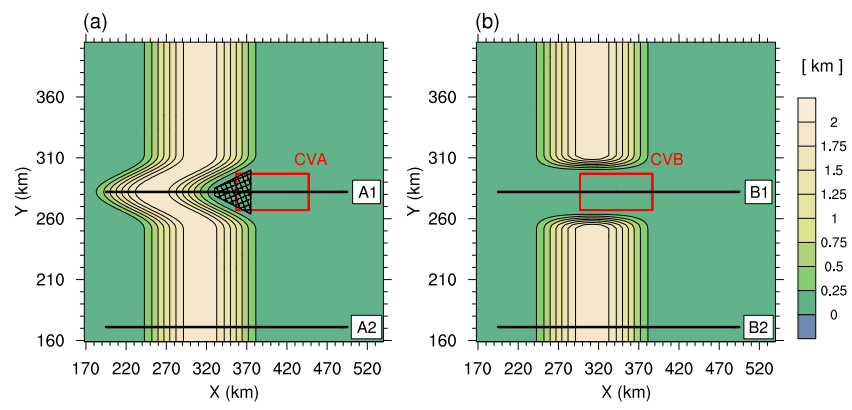

Fig. 1. Topography for the numerical simulations. (a) Mountain ridge with convex feature from Eq. (S1) (see Supplement 2). The cross-hatched area is the "semi-basin". The lines A1 and A2 indicate the location for cross-section for Figs. 2d, 2e, and 2f, respectively. (b) Mountain ridge with a gap from Eq. (S3) (see Supplement 2). Shading gives the terrain height, with the scale at right. Lines B1 and B2 indicate the location of the cross-sections for Figs. 3d, 3e, and 3f. Red lines mark areas used as the control volume for the momentum-budget analysis.

For example, the terrain of the northwestern Kanto region has a convex part (see Supplement 1). In this region, one of the convexity winds, the "Karakkaze", blows. The "Tokachi-kaze" in the Tokachi plain also has the same feature. Nishi and Kusaka (2019) found that a convex feature in a mountain range allows the downslope windstorms to more easily reach the leeward plain of the mountains. Hereafter, we call the strong wind at the leeward plain of the convex feature a "convexity wind". Spatial wind-distribution of convexity winds which is fan-shapes is very similar to that of gap wind. However, details of the similarities and differences between the convexity and gap winds are still poorly understood.

The similarities and differences between the downslope windstorms and gap winds by the previous studies have provided important information to understand the mechanisms of the strong winds in the lee of mountain range (e. g. Arakawa 1969; Gaberšek and Durran 2004). Hence, further understanding of the mechanisms can be expected by comparing the convexity and gap winds. Thus, we revealed the similarities and differences between the convexity and gap winds in terms of flow patterns, momentumbalances, and the impact of $F r_{m}$ using numerical simulations.

\section{Setup of numerical simulations}

We use here the advanced research version of the weather research and forecasting (WRF) model (Skamarock et al. 2008). The simulation domain consists of $210(\mathrm{X}) \times 190(\mathrm{Y})$ grid points with a horizontal grid spacing of $3.0-\mathrm{km}$. The height of the domain top is $20-\mathrm{km}$, covered vertically by 50 sigma levels. To prevent gravity-wave reflections, we use open boundary conditions for the lateral boundary conditions. Following Klemp and Lilly (1987), we also use an absorber layer near the domain top. The model configurations are summarized in Table 1.

As initial conditions, we use an idealized vertical atmosphere profile that is set to all grid points based on observations during a Karakkaze wind (Table 1). The environmental winds are westerly winds of $10 \mathrm{~m} \mathrm{~s}^{-1}$, independent of height. The lapse rate of potential temperature is $4.0 \times 10^{-3} \mathrm{~K} \mathrm{~m}^{-1}$ and the sea-level potential 
Table 1. Physical parameterization schemes, parameters, and initial conditions used in the simulations.

\begin{tabular}{ll}
\hline Planetary boundary layer & $\begin{array}{l}\text { Mellor-Yamada-Nakanishi-Niino scheme } \\
\text { (Mellor and Yamada 1982; } \\
\text { Nakanishi and Niino 2009) }\end{array}$ \\
$\begin{array}{l}\text { Roughness length } \\
\text { Initial windspeed }\end{array}$ & $10.01 \mathrm{~m} \mathrm{~s}$ \\
$\begin{array}{l}\text { Initial surface potential } \\
\text { temperature }\end{array}$ & $280 \mathrm{~K}$ \\
$\begin{array}{l}\text { Initial vertical gradient of } \\
\text { potential temperature }\end{array}$ & $4.0 \times 10^{-3} \mathrm{~K} \mathrm{~m}^{-1}$ \\
\hline
\end{tabular}

temperature is $280 \mathrm{~K}$. The ridge height is $2.0-\mathrm{km}$. These conditions give a mountain Froude number $F r_{m}$ of 0.42 . The numerical integration is run for 24 hours.

To simplify the treatment, we neglect the Coriolis force. Furthermore, we consider only dry, dynamical processes, and thus we neglect the surface sensible-heat and latent-heat fluxes. For the same reason, we do not use the shortwave, the longwave, and the cloud microphysics schemes.

To examine the difference between the convexity and gap winds, we use two ridge patterns in our experiments. Both experiments have a ridge height $H$ of $2.0-\mathrm{km}$ and a ridge width $L_{w}$ of $180-\mathrm{km}$. One is a mountain range with a convex part (Fig. 1a). The amplitude $A_{b}$ and the wavelength (exit-width) $L_{b}$ of the convexity are set to $60-\mathrm{km}$. Hereafter, the experiment with this terrain is called the convexity case. The plain area surrounded by slopes on three sides (hatched area in Fig. 1a) is called the "semi-basin". This semi-basin corresponds to that in the Kanto plain including the Maebashi (see Fig. S1). The leeward plain of the straight section of mountain corresponds to the leeward plain of Nikko mountain range (e.g. Utsunomiya in Fig. S1).

Another is a mountain range with a gap (Fig. 1b). Now, we want to compare the structure and mechanism of convexity and gap winds under the same exit-width of convexity and gap. Therefore, the wavelength for side-slope of the gap $\left(G_{L}\right)$ and the width of the bottom of the gap $\left(G_{W}\right)$ are set to $30-\mathrm{km}$, thus the total width of the gap $\left(G_{L}+G_{w}\right)$ is $60-\mathrm{km}$. Hereafter, the experiment with this terrain is called the gap case. The two terrains are summarized in the Supplement 2.

\section{Results and discussion}

\subsection{Flow patterns \\ a. Convexity case}

In the convexity case, the wind at $t=24$ hours exceeds $8 \mathrm{~m} \mathrm{~s}^{-1}$ at the semi-basin and the leeward plain of the semi-basin, starting near $x=320-\mathrm{km}$, and extending leeward about 100-km (Fig. $2 \mathrm{a})$. At the same time, the strongest winds and strongest surfacedivergence occurs at the leeward plain of the semi-basin near $x=$ $400-\mathrm{km}$. In contrast, at the $1.0-\mathrm{km}$ and $2.0-\mathrm{km}$ height, air flow into semi-basin resulting strong-convergence region exists at the slope of semi-basin (Figs. $2 \mathrm{~b}$ and $2 \mathrm{c}$ ). These results suggest that the flow converges around 1.0-2.0 km height and descends along the slope of the semi-basin, consequently, the flow diverges near the surface.

Indeed, in the $\mathrm{x}-\mathrm{z}$ cross-section along centerline A1 (Fig. 1a), the area with windspeed exceeding $20 \mathrm{~m} \mathrm{~s}^{-1}$ bends down from a $4.0-\mathrm{km}$ elevation to the ground surface at the leeward slope. This region has only downdrafts and isentropic lines that descend (Figs. $2 \mathrm{~d}$ and $2 \mathrm{e}$ ). In addition, the $284 \mathrm{~K}$ isentropic line descends from 1.25 to $0.25-\mathrm{km}$ elevation at the leeward plain of the semi-basin near $x=400-\mathrm{km}$ in Fig. 2b. In this region, strong downdrafts exceeding $0.5 \mathrm{~m} \mathrm{~s}^{-1}$ can be seen in the area from heights of $0.5-$ $1.0 \mathrm{~km}$. The horizontal position of the downdrafts corresponds to the region of strong divergence at $10 \mathrm{~m}$ (Fig. 2). These results suggest that hydraulic jumps do not exist at the slopes of semi-basin.

On the other hand, a hydraulic jump exists at the leeward
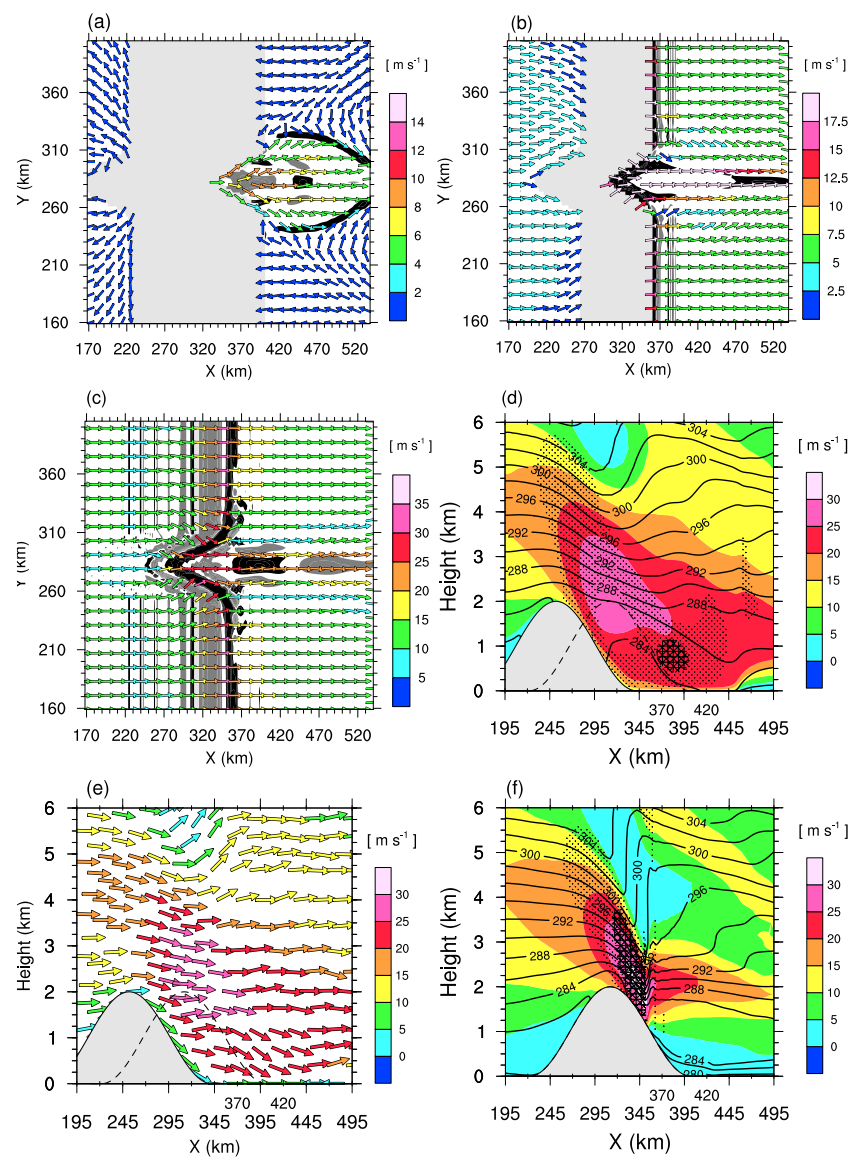

Fig. 2. Results for convexity case at $t=24$ hours. (a) Horizontal wind at $10 \mathrm{~m}$. The main gray area is the region with a terrain height above $10 \mathrm{~m}$. Vector color indicates windspeed (scale at right). Lee of the convex feature, the grey patches indicate regions of divergence exceeding $0.2 \mathrm{~s}^{-1}$, the black showing convergence exceeding $0.2 \mathrm{~s}^{-1}$. (b) Same as (a), except for values at $1.0-\mathrm{km}$. (c) Same as (a), except for values at $2.0-\mathrm{km}$. (d) Windspeeds, potential temperatures, and downdrafts of the cross-section A1 of Fig. 1a. Color shows windspeed (scale at right) and contours are potential temperature. Downdrafts in the dotted region exceed $0.1 \mathrm{~m} \mathrm{~s}^{-1}$ and in the cross-hatched region exceed $0.5 \mathrm{~s}^{-1}$. The light shaded area is within the ridge. The dashed line marks the profile of the main ridgeline. (e) Wind vectors composed of $u$ and $w$ of the cross-section A1 of Fig. 1a. Vector colors show the windspeed. (f) Same as (d), except for the cross-section A2 of Fig. 1a.

slope of the straight ridge section (e.g. cross-section A2 in Fig. 1a). In this cross-section, updrafts and ascent of isentropic lines appear over the slope of the mountain range (Fig. 2f). In addition, strong flow-convergence region appears at the mountain slope ( $x=$ about $360-\mathrm{km}$ in Figs. $2 \mathrm{~b}$ and 2c). Strong winds only appear at the windward of the convergence region and surface windspeed is small at the lee of the flow-convergence. These features correspond to the those of the hydraulic jump.

These results in the convexity case suggest that the flow-convergence (divergence) and downdrafts are important factors in the strong winds of the convexity winds.

\section{b. Gap case}

In the gap case, the strong-wind region appears and extends from the inside of the gap to leeward of the gap (i.e., from about $x=320 \mathrm{~km}$ in Fig. 3a), a similar region as the convexity case. Also, similar to the convexity case, the flow-divergence region appears at the exit of the gap from the lee of the gap. However, the gap winds are stronger than the convexity winds. Additionally, the strongest winds appear more upwind than those in the convexity case $(x=320-\mathrm{km})$. At the $1.0-\mathrm{km} \mathrm{m}$ and $2.0-\mathrm{km}$, strong 

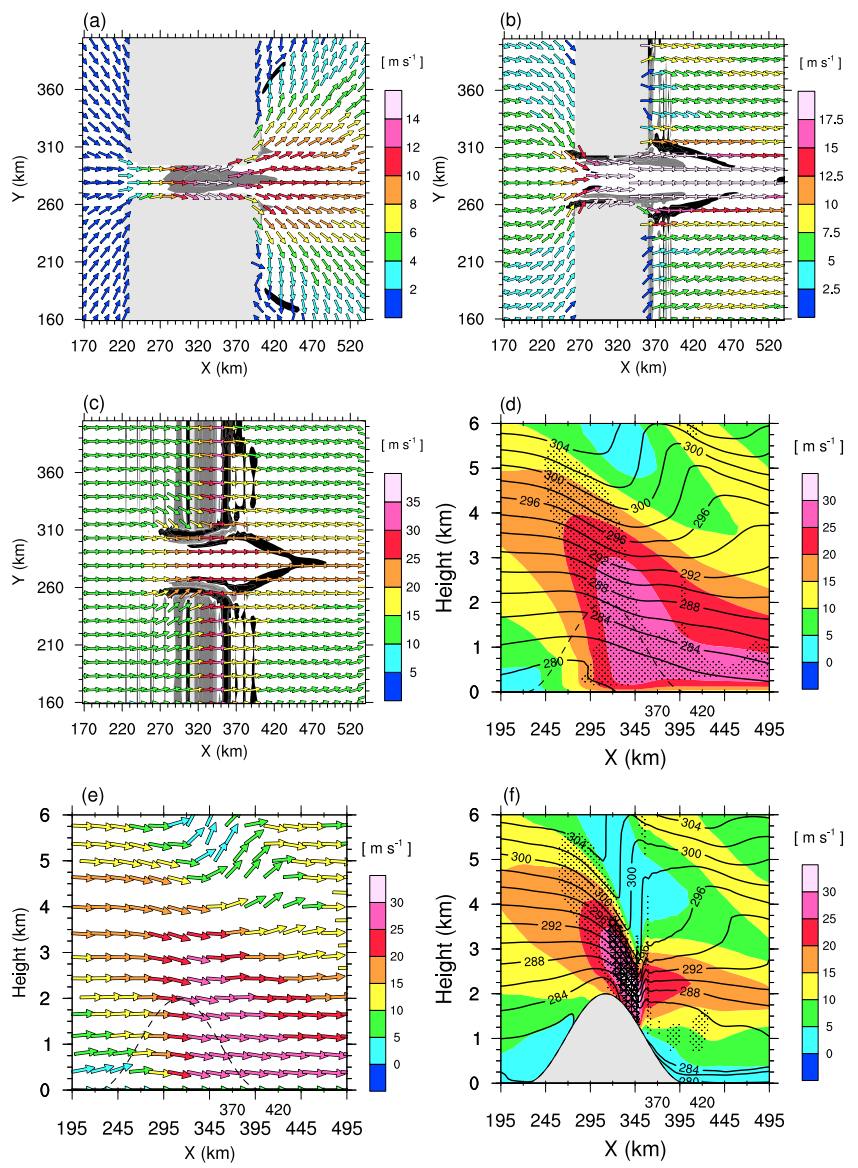

Fig. 3. Results for the gap case. (a) Same as in Fig. 2a. (b) Same as in Fig. 2b. (c) Same as in Fig. 2c. (d) Same as in Fig. 2d, except for the crosssection B1 of Fig. 1b. (e) Same as in Fig. 2e, except for the cross-section B1 of Fig. 1b. (f) Same as in Fig. 2f, except for the cross-section B2 of Fig. 1b.

flow-convergence does not appear at the entrance of gap unlike the convexity winds (Figs. $3 b$ and $3 c$ ), nevertheless, the strongwind region extends to leeward of a gap like the convexity winds. These results suggest that convergence in the entrance of the gap is not important in the formation of gap winds, unlike the convexity winds.

Along the gap's centerline B1 (Fig. 1b), the region with $U$ exceeding $25 \mathrm{~m} \mathrm{~s}^{-1}$ extends leeward from the gap (near $x=295-\mathrm{km}$ ) below 4.0-km height (Figs. 3d and 3e). In addition, the isentropic lines along the cross-section descend gently. At the same time, weak downdrafts of less than $0.25 \mathrm{~m} \mathrm{~s}^{-1}$ appear inside of the gap (Fig. 3d).

At the leeward slope of the straight ridge section (e.g. crosssection B2 in Fig. 1b), surface windspeed is small at the leeward plain resulting a hydraulic jump appears, as same as the convexity case (Figs. 3b, 3c, and 3f).

This flow pattern in the gap case is consistent with that of "the mountain wave regime", described in Gaberšek and Durran (2004). In that study, the mountain-wave regime appears when $F r_{m} \sim 0.67$. In this regime, a high acceleration of the gap wind occurs within the exit region.

These results in the gap case suggest that the flow-convergence and downdrafts are not so important in the strong winds of the gap winds, unlike the convexity winds. Therefore, there are other important factors of the mechanism of gap winds.

\subsection{Momentum budgets}

The previous section shows that both cases have similar spatial surface flow-patterns. However, there are some differences

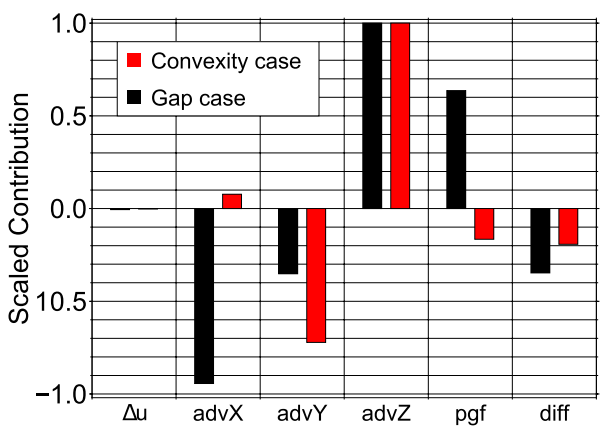

Fig. 4. Momentum-balance terms for the convexity (red) and gap (black) cases, normalized to their largest term. Values are for the x-component of momentum and averaged over the control volume (Fig. 1) for three hours. The terms are $\Delta u=$ transient, $a d v X=\mathrm{x}$-direction momentum-flux convergence, $a d v Y=\mathrm{y}$-direction momentum-flux convergence, $a d v Z=$ z-direction momentum-flux convergence, $p g f=$ pressure gradient, and diff $=$ diffusion term

of three-dimensional structure between both cases. To clarify the cause of these differences, we analyze the momentum budget for the x-component of momentum in both cases. The analyses are done in the control volumes shown in Fig. 1. These control volumes are oriented along the centerline of the valley and in the strong-wind regions of both cases. Each volume has dimensions 90-km (X) × 30-km (Y) × 1.0-km (Z).

Integrating the $\mathrm{x}$-momentum equation over a control volume, we have

$$
\begin{aligned}
\int_{V} \frac{\partial \rho u}{\partial t} d V= & -\int_{V} \frac{\partial \rho u u}{\partial x} d V-\int_{V} \frac{\partial \rho u v}{\partial y} d V-\int_{V} \frac{\partial \rho u w}{\partial z} d V \\
& -\int_{V} \frac{\partial p}{\partial x} d V+\int_{V} \text { others } d V
\end{aligned}
$$

Here, $V$ is the control volume, $\partial \rho u / \partial t$ is a transient term, $-\partial \rho u u / \partial x,-\partial \rho u v / \partial y$ and $-\partial \rho u w / \partial z$ divergence terms of gridscale momentum fluxes in the $x, y$, and $z$ directions, and $-\partial p / \partial x$ is a pressure-gradient term. Others are a sum of other terms that roughly equals the sum of divergence terms of sub-grid-scale momentum fluxes. We call this term the "diffusion term". Hereafter, "momentum fluxes" means the grid-scale momentum fluxes.

For the analyses, we integrated each term over each control volume and calculated averages of these integrated values over the analysis period. The analysis period started after the simulations ran for 21 hours and finished after 24 hours.

Figure 4 shows the values for all terms of the momentum budget analysis, normalized by the largest term. For all listed terms, a positive value indicates that the momentum has increased in the control volume. In both the convexity and gap cases, the transient term $\Delta u$ nearly equals 0 in the control volume, indicating that the $\mathrm{x}$-component of the momentum balance has reached a steady state.

In the convexity case, the grid-scale momentum divergence and convergence terms are dominant while the contribution of the pressure-gradient and diffusion terms are less than $20 \%$ of Zdirection convergence:

$$
\text { divergence terms }(\mathrm{Y}) \fallingdotseq \text { convergence terms }(\mathrm{Z}) \text {. }
$$

Hence, the flow which descends the slope of the semi-basin and diverges near the ground at the semi-basin can be confirmed also by the result of momentum budget analysis. Here, note that the contribution of the pressure gradient is small. This result suggests that the local pressure gradient in the semi-basin is not important in the formation of the convexity wind but the synopticscale pressure gradient is important to maintain the general winds.

In the gap case, the momentum balance is as follows: 
Table 2. Impact of the $F r_{m}$ in the convexity and gap cases. $l$ indicates scorer parameter $(N / U$, where $N$ and $U$ are Brant-Vaisala frequency and windspeed, respectively). The circles (crosses) indicate that windspeed exceeds (does not exceed) $8 \mathrm{~m} \mathrm{~s}^{-1}$ at the leeward plain in each cross-section.

\begin{tabular}{|c|c|c|c|c|c|}
\hline \multirow{3}{*}{$F r_{m}$} & \multirow{3}{*}{$l\left[\mathrm{~s}^{-1}\right]$} & \multicolumn{4}{|c|}{ Strong wind (windspeed $>8 \mathrm{~m} \mathrm{~s}^{-1}$ ) } \\
\hline & & \multicolumn{2}{|c|}{ Convexity case } & \multicolumn{2}{|c|}{ Gap case } \\
\hline & & Cross-section A1 & Cross-section A2 & Cross-section B1 & Cross-section B2 \\
\hline 0.21 & $2.4 \times 10^{-3}$ & $\times($ absence $)$ & $\times$ & $\circ($ presence $)$ & $\times$ \\
\hline 0.42 & $1.2 \times 10^{-3}$ & 0 & $\times$ & $\circ$ & $x$ \\
\hline 0.63 & $8.0 \times 10^{-4}$ & ० & $\times$ & o & $\times$ \\
\hline 0.83 & $6.0 \times 10^{-4}$ & $\circ$ & $\times$ & o & $x$ \\
\hline 1.04 & $4.8 \times 10^{-4}$ & ○ & $\times$ & o & $\times$ \\
\hline 1.25 & $4.0 \times 10^{-4}$ & ○ & $\circ$ & o & ० \\
\hline 1.48 & $3.3 \times 10^{-4}$ & ○ & ○ & o & o \\
\hline 1.67 & $3.0 \times 10^{-4}$ & o & ० & o & o \\
\hline
\end{tabular}

divergence terms $(\mathrm{X})+$ divergence terms $(\mathrm{Y})+$ diffusion term

$\fallingdotseq$ convergence terms $(\mathrm{Z})+$ pressure-gradient terms.

These momentum-balance terms in the gap case are consistent with those of "the mountain wave regime" as described in Gaberšek and Durran (2004).

As same as the convexity case, the flow-descent and flowdivergence are important in the formation of gap winds. Moreover, the pressure-gradient term is more dominant than that in the convexity case. These results suggest that the local pressure gradient in the gap is important in the formation of the gap winds, unlike the convexity case.

\section{3 impact of the mountain Froude number on the convexity and gap cases}

When the mountain Froude number $\left(F r_{m}\right)$ changes, the flowpattern of the downslope windstorms and gap winds also change (e.g. Lin and Wang 1996; Gaberšek and Durran 2004). Now, we confirm that the difference in the impact of $F r_{m}$ between the convexity and gap winds by examining the results of sixteen experiments with various $F r_{m}$ values (Table 2).

When $F r_{m}$ is between 0.42 and 1.04 , the convexity and gap winds appear. The reasons are the same as the experiments described in the previous sections $\left(F r_{m}=0.42\right)$.

When $F r_{m}$ is 0.21 , strong surface winds do not blow at the leeward plain in the convexity case because hydraulic jumps appear above the entire leeward slope. In contrast, in the gap case, strong surface winds blow at the leeward plain of the gap section. It is because that the air in the upwind region can go around the mountain range and flows through the gap section.

When $F r_{m}$ exceeds 1.25 , a strong surface winds appear in the entire leeward plain because the hydraulic jump does not appear above the entire leeward slope. In other words, the effects of the convexity and gap cannot be seen.

These results suggest that both convexity and gap make hydraulic jumps hard to appear, compared with the leeward slope of the straight ridge section. However, the cause is different between each other. The cause in the convexity case is that the convexity tends to produce the downdraft and surface divergence at the lee of the mountain. In contrast, the cause in the gap case is that the local $F_{m}$ in the gap is very large and potential-flows appear in the gap.

\section{Conclusions}

In the present study, we numerically simulated the flow patterns around two idealized features in a mountain range. One feature was a convex feature, the other a gap. We then examined how these features affected the local winds in the leeward plain. Our main results are the following.

- Under the typical value of mountain Froude number of the winter season in Japan $\left(F r_{m}=0.42\right)$, both cases produced strong local winds at the leeward plain of the mountain range. However, for the convexity case, the strongest wind occurred in the leeward plain area, whereas the gap case had its strongest wind in the gap.

- The convexity case had strong downdrafts over the strong-wind region, whereas the gap case had weak downdrafts over the strong-wind region.

- The momentum budgets in the strong-wind region differed between the two cases, indicating different driving mechanisms for the strong wind. In the convexity case, the downdrafts maintained the strong-wind region at the leeward plain of the semi-basin. But for the gap case, both the pressure-gradient force and the downdrafts in the gap maintained the strong-wind region.

- Sensitivity experiments of $F r_{m}$ showed that the convexity and gap winds appear when $F r_{m}$ is between 0.42 and 1.04. In contrast, when $F r_{m}$ is 0.21 , the gap winds appear because the flow can go around the gap, but the convexity winds do not appear. When $F r_{m}$ exceeds 1.25, strong surface winds appear in the entire leeward plain.

- These result suggested that both convexity and gap have an effect that hydraulic jumps hard to appear over the mountain slope, compared with the leeward slope of the straight ridge section. However, the cause is different between each other. In the convexity case, the cause is that the downdraft and surface flow-divergence tend to appear at the lee of the semi-basin. In the gap case, the cause is that local $F r_{m}$ in the gap is very large and potential-flows appear in the gap.

- Thus, although their spatial patterns of surface wind are similar to each other, their mechanisms for producing a strong local wind differ. The convexity winds may be important in the formation of some local winds when a semi-basin, instead of a gap, exists at the windward of the strong-wind region even if local winds is categorized as a gap wind.

\section{Acknowledgments}

This work was supported by Cabinet Office, Government of Japan, Cross-ministerial Strategic Innovation Promotion Program (SIP), "Technologies for creating next-generation agriculture, forestry and fisheries" (funding agency: Bio-oriented Technology Research Advancement Institution, NARO).

Edited by: M. Yoshizaki

\section{Supplement}

Supplement 1 shows the example of terrain with convex features (Fig. S1).

Supplement 2 shows the detail settings of terrain. 


\section{References}

Arakawa, S., 1969: Climatological and dynamical studies on the local strong winds, mainly in Hokkaido. Japan. Geophys. Mag., 34, 349-425.

Clark, T. L., and W. R. Peltier, 1984: Critical level reflection and the resonant growth of nonlinear mountain waves. J. Atmos. Sci., 41, 3122-3134.

Elvidge, A. D., and I. A. Renfrew, 2016: The causes of foehn warming in the lee of mountains. Bull. Amer. Meteor. Soc., 97, 455-466, doi:10.1175/BAMS-D-14-00194.1.

Gaberšek, S., and D. Durran, 2004: Gap flows through idealized topography. Part I: Forcing by large-scale winds in the nonrotating limit. J. Atmos. Sci., 61, 2846-2862, doi:10.1175/ JAS-3340.1.

Gohm, A., G. J. Mayr, A. Fix, and A. Giez, 2008: On the onset of bora and the formation of rotors and jumps near a mountain gap. Quart. J. Roy. Meteor. Soc., 134, 21-46, doi:10.1002/ qj.206.

Klemp, J. B., and D. K. Lilly, 1987: Numerical simulation of hydrostatic mountain waves. J. Atmos. Sci., 35, 78-107.

Lackmann, G. M., and J. E. Overland, 1989: Atmospheric structure and momentum balance during a gap-wind event in Shelikof Strait, Alaska. Mon. Wea. Rev., 117, 1817-1833, doi:10.1175/1520-0493(1989)117,1817:ASAMBD.2.0.CO;2.

Lilly, D. K., and E. J. Zipser, 1972. The front range windstorm of 11 January 1972 -A meteorological narrative. Weatherwise, 117, 2041-2058.

Lin, Y., and T. Wang, 1996: Flow regimes transient dynamics of two-dimensional flow over an isolated mountain ridge. $J$. Atmos. Sci., 53, 139-158.

Long, R. R., 1954: Some aspects of the flow of stratified fluid system. Tellus., 6, 97-115.

Mass, C., M. D. Warner, and R. Steed, 2014: Strong westerly wind events in the strait of Juan de Fuca. Wea. Forecasting, 29, 445-465.

Mayr, G. J., L. Armi, S. Arnold, R. M. Banta, L. S. Darby, D. R. Durran, C. Flamant, S. Gaberšek, A. Gohm, R. Mayr, S. Mobbs, L. B. Nance, I. Vergeiner, J. Vergeiner, and C. D. Whiteman, 2004: Gap flow measurements during the Mesoscale Alpine Programme. Meteorol. Atmos. Phys., 86, 99119.

Mellor, G. C., and T. Yamada, 1982: Development of a turbulence closure model for geophysical fluid problems. Rev. Geophys. Space Phys., 20, 851-875.

Miltenberger, A. K., S. Reynolds, and M. Sprenger, 2016: Revisiting the latent heating contribution to foehn warming: Lagrangian analysis of two foehn events over the Swiss Alps. Quart. J. Roy. Meteor. Soc., 142, 2194-2204, doi: 10.1002/qj.2816.

Nakanishi, M., and H. Niino, 2009: Development of an improved turbulence closure model for the atmospheric boundary layer. J. Meteor. Soc. Japan, 87, 895-912.

Nishi, A., and H. Kusaka, 2019: Effect of mountain convexity on the locally strong "Karakkaze" wind. J. Meteor. Soc. Japan (under revision).

Peltier, W. R., and T. M. Clark, 1979: The evolution and stability of finite-amplitude mountain waves. Part 2: Surface wave drag and severe downslope windstorms. J. Atmos. Sci., 36, 1498-1529.

Saito, K., 1993: A numerical study of the local downslope wind "Yamaji-kaze" in Japan. Part 2: Non linear aspect of the 3D flow over a mountain range with a col. J. Meteor. Soc. Japan, 71, 247-272.

Saito, K., and M. Ikawa, 1991: A numerical study of the Local Downslope wind "Yamaji-kaze" in Japan. J. Meteor. Soc. Japan, 69, 31-56.

Sasaki, K., M. Sawada, S. Ishii, H. Kanno, K. Mizutani, T. Aoki, T. Itabe, D. Matsushima, W. Sha, A. T. Noda, M. Ujiie, Y. Matsuura, and T. Iwasaki, 2010: The temporal evolution and spatial structure of the local easterly wind "Kiyokawa-dashi" in Japan. Part II: Numerical simulations. J. Meteor. Soc. Japan, 88, 161-181.

Scorer, R., 1952: Mountain-gap winds; a study of surface wind at Gibraltar. Quart. J. Roy. Meteor. Soc., 78, 53-61.

Skamarock, W. C., J. B. Klemp, J. Dudhia, D. O. Gill, D. M. Barker, M. G. Duda, X. Huang, W. Wang, and J. G. Powers, 2008: A description of the Advanced Research WRF version 3. NCAR Tech. Note, NCAR/TN-475+STR, $126 \mathrm{pp}$.

Smith, R. B., 1985: On severe downslope winds. J. Atmos. Sci., 42, 2597-2603

Zängl, G., 2003: Deep and shallow south foehn in the region of Innsbruck: Typical features and semi-idealized numerical simulation. Meteor. Atmos. Phys., 83, 237-261.

Manuscript received 11 October 2018, accepted 12 December 2018 SOLA: https://www.jstage.jst.go.jp/browse/solal 